\title{
POLÍTICA E ANÁLISE DO DISCURSO NA ARQUEOLOGIA DE FOUCAULT
}

\author{
Daniel Verginelli Galantin ${ }^{1}$ \\ Thiago Fortes Ribas ${ }^{2}$
}

\begin{abstract}
Resumo: $\mathrm{O}$ artigo procura explorar a relação entre a análise do discurso e a política na arqueologia de Michel Foucault. O artigo começa por levantar a questão sobre a forma como se poderia abordar o seu trabalho, uma vez que ele critica a função autor. Mostraremos que esta abordagem já se constitui como um dos princípios teóricos de sua arqueologia. Investigaremos, em um segundo momento, como as operações críticas da sua análise das práticas discursivas conduzem a uma politização do saber, feita em oposição ao pensamento antropológico moderno.
\end{abstract}

Palavras-chave: Foucault - política - discurso - arqueologia - autor.

\section{INTRODUÇÃO}

O que é a política no pensamento de Michel Foucault?

Ora, tal pergunta nos coloca de saída diante de problemas que, levando em consideração as suas críticas, Foucault não nos permite uma resolução simples. Podemos notar, inicialmente, que seus principais textos não propõem uma definição objetiva ou permanente da noção de política. Não há, tampouco, em seus trabalhos uma análise histórica da formação e do funcionamento da política semelhante ao modo como são problematizadas, por exemplo, as noções da loucura, do homem ou da sexualidade. Sobre tais noções, Foucault frequentemente contornou as perguntas que demandam suas definições essenciais para investigar o nascimento histórico de sistemas de pensamento nos quais elas têm lugar. Nenhuma dessas noções são compreendidas a partir de uma essencialidade, mas são cindidas nas singularidades históricas que a pesquisa foucaultiana faz aparecer nas relações entre palavras e coisas. Caso houvesse em seu trabalho um questionamento similar específico sobre a noção da política, podemos apenas supor que a estratégia foucaultiana seria a mesma. Na recusa de propor uma identidade fixa à noção, parece legítima a suposição de que seria desenvolvida uma problematização dos modos como diferentes identidades lhe foram construídas. Tal problematização se faria através do estudo de correlações entre práticas discursivas e não-discursivas que compõem os jogos de verdade

\footnotetext{
${ }^{1}$ Professor da Universidade Estadual de Londrina. Doutor em Filosofia pela Universidade Federal do Paraná com estágio sanduíche na Université de Paris Est-Créteil.

2 Professor da Universidade Federal do Rio de Janeiro. Doutor em Filosofia pela Universidade Federal do Paraná com estágio sanduíche na Université de Paris Est-Créteil.
} 
de um período histórico determinado em nossa sociedade. No entanto, não há um trabalho específico de Foucault sobre esta noção.

Em segundo lugar - e aqui trata-se de algo que coloca em questão a validade da própria pergunta levantada -, muitos dos seus textos não nos autorizam sequer a pressupor uma fixidez no pensamento do autor. ${ }^{3}$ Não são meras frases de efeito as habituais passagens em que Foucault rejeita a si mesmo um rosto, uma identidade ou um lugar fixo de onde ele falaria. A escrita aparece em seus textos não como instrumento para transpor seu pensamento, mas como experiência de apagamento e transformação de si. ${ }^{4}$ Ademais, em seus textos, nos quais, levando adiante um hábito corriqueiro da história das ideias, se poderia supor que seu pensamento se manifestaria, a noção de autor como núcleo primeiro de racionalidade e fonte de sentido é fortemente contestada.

No que diz respeito à crítica da "função autor" 5 , temos uma problematização que Foucault dirige a si mesmo, não deixando de se questionar no momento em que assume esta função. Sobre este ponto é importante notar que, mesmo que não se recuse a comentar seus trabalhos anteriores, por vezes, de modo emblemático, Foucault demonstrou algumas ressalvas ao fazê-lo. Mencionamos aqui dois exemplos: primeiro, da sua advertência ao perigo de "se estabelecer a monarquia do autor" na escrita de um novo prefácio ao seu livro antigo, na ocasião da reedição de História da loucura em 1972; e segundo, de sua utilização do pseudônimo Maurice Florence (formando suas iniciais M.F.) em um dicionário de filósofos para a escrita do verbete intitulado Michel Foucault. ${ }^{7}$ Assim, além das constantes rejeições de um identidade fixa ao seu pensamento, vemos que a utilização de um pseudônimo para escrever um verbete sobre si mesmo e a recusa de direcionar o seu leitor em um prefácio nos mostram alguns cuidados que dizem respeito ao modo como Foucault problematiza, acerca de si e de seus trabalhos, a relação entre o autor e os seus discursos.

Considerando as questões mencionadas, nos surge a seguinte interrogação: perguntar-se sobre o pensamento do autor Foucault não traria o perigo de fomentar um modo de se fazer a história das ideias apoiado em uma noção de autoria contrária ao que ele mesmo defende em sua pesquisa? Não seria mais prudente começarmos pela investigação de

\footnotetext{
${ }^{3}$ Sobre a impossibilidade de se traçar uma identidade ao pensamento de Foucault, é suficiente lembrarmos da conhecida passagem de L'archéologie du savoir: "Vários, como eu sem dúvida, escrevem para não ter mais fisionomia. Não me perguntem quem sou e não me diga para permanecer o mesmo: é uma moral de estado civil; ela rege nossos papéis. Que ela nos deixe livres quando se trata de escrever”. (p. 28).

${ }^{4}$ O caráter de uma experiência transformadora de sua escrita é explorado em uma entrevista publicada em 1980 com Tombradori: "meus livros são para mim experiências, em um sentido que eu gostaria o mais pleno possível. Uma experiência é algo de que saímos nós mesmos transformados [on sort soi-même transformé]. Se eu devesse escrever um livro para comunicar aquilo que já penso, antes de ter começado a escrever, eu não teria nunca a coragem de o empreender. Eu só o escrevo porque não sei ainda exatamente o que pensar desta coisa que eu gostaria tanto de pensar. De modo que o livro me transforma e transforma aquilo que penso. [...] Sou um experimentador, neste sentido que escrevo para mudar a mim mesmo e não pensar mais a mesma coisa que antes”. FOUCAULT, "Entretien avec Michel Foucault", Dits et écrits IV, p. 41-42.

${ }^{5}$ FOUCAULT, “Qu'est-ce qu'un auteur?”, Dits et écrits I, p. 799.

${ }^{6}$ FOUCAULT, Histoire de la folie à l'âge classique, p. 10.

${ }^{7}$ FOUCAULT, "Foucault", Dits et écrits IV, pp. 631-636.
} 
uma relação possível entre a sua crítica da função autor, os princípios teóricos de sua pesquisa e o seu modo de pensar a política?

\section{FUNÇÃO AUTOR E ANÁLISE DAS PRÁTICAS DISCURSIVAS}

Interrogando historicamente as práticas discursivas sobre o nascimento da função autor, somos levados pela letra de Foucault a assumir como ponto de partida apenas os fatos materiais de uma multiplicidade de discursos proferidos. Admite-se, no início, somente "uma população de acontecimentos dispersos". ${ }^{8}$ É a partir de dados discursivos, através de um conjunto de escolhas estratégicas, que se constrói um autor. A atribuição de um autor não é importante para todo tipo de discurso. Entretanto, de acordo com a ordem discursiva vigente em uma sociedade, vemos que a ligação dos discursos a um nome de autor confere valor a determinado conjunto de enunciados e, simultaneamente, institui o autor como uma função que atua "como princípio de agrupamento do discurso, como unidade e origem de suas significações, como foco de sua coerência." "9 O importante aqui é perceber $o$ autor ou $o$ pensamento do autor como derivados, como resultados de procedimentos possíveis (não necessários) e variáveis de acordo com a perspectiva adotada. Para Foucault, o autor não é o critério evidente e imediato da unidade dos discursos proferidos por alguém, mas sim uma produção discursiva complexa que é naturalizada e, portanto, mascarada por pressupostos irrefletidos na adoção de uma ordem discursiva. ${ }^{10}$ Assim, a suposição da existência de um pensamento do autor que seria meramente transposto na linguagem enunciada mostra-se ingênua, ao mesmo tempo em que perpetua uma forma de empobrecimento da análise teórica dos discursos. Os riscos de tal ingenuidade não são poucos, uma vez que os procedimentos de construção de um autor - na valorização do que foi dito, do que deve ser preservado, do que ganha o estatuto de obra ou do que vigora como verdade, ou ainda, na adoção dos pressupostos transcendentais do sujeito que constituiria soberanamente as significações de seu discurso - não são percebidos nas posições estratégicas que ocupam.

A análise foucaultiana das práticas discursivas sobre os procedimentos que atuam em um material de enunciados organizando a função autor visa, justamente, atuar de modo a torná-los visíveis impedindo que sejam assumidos inadvertidamente. De um lado, a função autor contribuiria para o apagamento das práticas discursivas como material de análise. Por outro lado, com a análise das práticas discursivas considera-se como dados primeiros apenas os enunciados proferidos para investigar os sistemas históricos de práticas que os envolvem e os tornam possíveis. Para Foucault, quando se assume o autor e seu pensamento como dados naturais e como o centro de toda organização discursiva, desvaloriza-se os discursos, não atentando às regras de suas formações e de seus funcionamentos. Assim, a história das ideias daria continuidade a um tipo trabalho sobre o pensamento que, através de temas vagos e incertos como os da intenção do autor, da genialidade, da influência ou da tomada de consciência, referia-se somente ao que é exterior ao discurso, ou seja, um trabalho histórico

\footnotetext{
${ }^{8}$ FOUCAULT, "Sur l'archéologie des sciences. Réponse au Cercle d'épistémologie", Dits et écrits I, p. 701.

${ }^{9}$ FOUCAULT, L'ordre du discours, p. 28.

${ }^{10}$ FOUCAULT, “Qu'est-ce qu'un auteur?”, Dits et écrits I, p. 790.
} 
que desviaria o problema das regras históricas dos discursos para manter a crença na "soberania do sujeito, ou da consciência". ${ }^{11}$ Em oposição, para Foucault, a análise discursiva deve interrogar a construção e as alterações possíveis da função do sujeito nas variadas formas de enunciação, ou seja, questionar as formas de enunciação nas suas produções de sujeitos. Assim, como afirma Salma Tannus Muchail, quando Foucault tematiza a "funçãoautor como uma particularização possível da função-sujeito", trata-se de trocar a pergunta acerca do sujeito originário ou constituinte pela pergunta sobre "sua constituição enquanto função do discurso." "12 A admissão impensada da função autor traz consigo os problemas da centralidade de um sujeito. Já o questionamento dessa função possibilita justamente a dissolução desta centralidade, uma vez que o papel do sujeito passa a ser visto em funções atribuídas pelas práticas discursivas, e não o contrário.

Podemos lembrar, neste sentido, que na conferência $O$ que é um autor?, Foucault se mostra desconfiado precisamente de alguns elementos da crítica literária e filosófica contemporânea que arriscariam reintroduzir as figuras do autor e da obra. Para Foucault, as noções de obra e de escrita arriscavam bloquear os novos espaços e funções livres que se tornam possíveis com o desaparecimento do autor. A análise da obra, apesar de não fazer apelo à consciência do autor, ao estabelecer como campo a estrutura e arquitetura interna dos textos, reconduz à questão de qual seria a instância que lhe confere unidade. Ao final, seria necessário interrogar qual o limite de uma obra ${ }^{13}$, se são incluídas cartas, rascunhos, bilhetes de recados ou mesmo as provas de ensino fundamental do autor quando criança.

A noção de escrita, por sua vez, não se foca nem no gesto de escrever, nem no signo escrito. Mas ao se esforçar em delimitar um espaço geral em que toda escrita se desenvolve, seu espaço e tempo de desenvolvimento e dispersão, a noção de escrita pode acabar assumindo, num plano transcendental, as mesmas funções que a autoria assumia no plano empírico:

Eu me pergunto se, ao ser reduzida ao seu uso corrente, essa noção não transpõe, num anonimato transcendental, as características empíricas do autor. De fato, conferir à escrita um estatuto originário não seria uma maneira de retraduzir em termos transcendentais, de um lado, a afirmação teológica de seu caráter sagrado e, de outro lado, a afirmação crítica de seu caráter criador? Admitir que a escrita de alguma forma é, pela história que a tornou possível, submetida à prova do esquecimento e da repressão, por acaso isso não é representar, em termos transcendentais, o princípio religioso do sentido escondido (com a necessidade de interpretá-lo) e o princípio crítico das significações implícitas, das determinações silenciosas, dos conteúdos obscuros (com a necessidade de comentar)? Finalmente, pensar a escrita como ausência não seria simplesmente repetir, em termos transcendentais, o princípio religioso da tradição simultaneamente inalterável e

\footnotetext{
${ }^{11}$ FOUCAULT, “Qui êtes-vous, professeur Foucault?”, Dits et écrits I, p. 609.

12 MUCHAIL, "Michel Foucault e o dilaceramento do autor", p. 132.

${ }^{13}$ FOUCAULT, “Qu'est-ce qu'un auteur?”, Dits et écrits I, p. 794.
} 
nunca completa, e o princípio estético da sobrevida da obra, de sua manutenção para além da morte, e de seu excesso enigmático com relação ao autor? ${ }^{14}$

O tema recorrentemente perseguido da exegese de um sentido sagrado de uma escrita, um sentido jamais completamente enunciado, ou a suposição de uma criação de significações misteriosamente silenciosas trabalhariam, segundo Foucault, na retomada dos temas transcendentais ligados às operações de negação das regras históricas do funcionamento do discurso enquanto elemento de análise. Perpetuar a crença nas significações jamais completamente enunciadas é uma forma de manter a fonte de sentido do pensamento como exterior ao discurso. O discurso aparece, assim, somente como espelho "daquilo que se pensa." 15 Contra estes temas, no caso de adotarmos uma perspectiva foucaultiana, é preciso reafirmar a importância do discurso e da análise das práticas discursivas. Neste sentido, seria preciso afirmar a possibilidade de "uma análise dos discursos que escapará da fatalidade do comentário, não supondo nenhum resto, nenhum excesso naquilo que é dito, mas somente o fato de sua aparição histórica." 16 Para Foucault, não será o pensamento do autor, como consciência intencional ou fonte de significações criativas e uma inacessível genialidade, nem a sua obra, como unidade coerente de sentido, e nem a sua escrita enquanto espaço de um anonimato transcendental, aquilo que se analisa nas práticas discursivas. $\mathrm{Na}$ análise das práticas discursivas, não se tratará de nenhuma interioridade misteriosa do pensamento ligada à infinita necessidade do comentário, sempre incapaz de revelar o segredo perdido na transposição do pensamento à linguagem. Ao contrário, em sua análise se permanecerá na exterioridade dos acontecimentos históricos materializados nos discursos.

Pois bem, somos levados a concluir que os mesmos argumentos da crítica foucaultiana à função autor - ou nas reinserções das figuras da obra e da escrita - podem ser endereçados a quem pretender explicar as intenções não ditas do seu próprio pensamento. Voltando à questão de onde partimos, podemos dizer que, se Foucault não nos oferece uma forte definição do que é a política, seria pouco coerente com os seus trabalhos críticos querer encontrar uma definição desta noção em um não dito de seu pensamento. Como proceder, então, diante da pergunta inicial deste artigo? Ao que parece, mostra-se necessária sua reformulação. Antes de pressupor um pensamento de Foucault que conteria uma noção de política a ser explicitada, seria mais coerente com os princípios teóricos desenvolvidos em muitos de seus discursos (e, talvez, possamos dizer que seria mais honesto com suas análises discursivas) propor uma outra abordagem.

Por conseguinte, propomos adiante tratar do modo como a dimensão política de seu trabalho está relacionada à crítica de pressupostos irrefletidos e naturalizados nos regimes discursivos em vigor. É justamente este tipo de crítica que está em jogo na problematização da noção de autor. Da mesma maneira, no questionamento sobre noções como a loucura, o homem ou a sexualidade, Foucault criticou a naturalização das construções recentes de seus regimes de verdade através de análises discursivas que mostravam as suas contingências.

\footnotetext{
${ }^{14}$ FOUCAULT, “Qu'est-ce qu'un auteur?”, Dits et écrits I, p. 795.

${ }^{15}$ FOUCAULT, Le beau danger. Entretien avec Claude Bonnefoy, p. 34.

${ }^{16}$ FOUCAULT, Naissance de la clinique, p. XIII.
} 
Opondo-se a supostas necessidades, suas análises discursivas parecem promover uma politização dos saberes, abrindo fissuras nas cristalizações dos regimes de verdade e, portanto, diminuindo a eficácia de relações de poder que permaneciam veladas.

Seguimos, então, não com a pergunta sobre o que é a política em seu pensamento, uma vez que tal pergunta parece trazer consigo prejuízos denunciados em seus próprios trabalhos quando critica certas "facilidades" presentes amiúde na história das ideias. ${ }^{17}$ Diversamente, partimos do questionamento sobre a relação entre os princípios teóricos de suas análises discursivas e o que aparece como uma ampliação do campo da política em seus trabalhos. Assim, a pergunta inicial é reformulada nos seguintes termos: como as análises discursivas foucaultianas possibilitam a transformação daquilo que se entende como campo da política?

\section{ARQUEOLOGIA, CRÍTICAE POLÍTICA}

Constantemente no trabalho de Foucault somos levados à percepção de que quaisquer de nossas práticas, por mais cotidianas e inocentes que nos pareçam, sendo percebidas em sua historicidade, poderão ser politicamente transformadas. $\mathrm{O}$ ato de politizar as nossas práticas é algo que pode ser compreendido através de uma compreensão ampliada do campo da política. Para Foucault, trata-se de mostrar que "existem possibilidades de ação, uma vez que é através de certo número de ações, de reação, através certo número de lutas, de conflitos, para responder a certo número de problemas, que escolhemos essas soluções." 18 Politizar seria, então, devolver a mobilidade ao que estava enrijecido pelo status de evidência anterior à crítica. Notamos, deste modo, que a força política de seus trabalhos críticos está intimamente ligada à sua recusa em aceitar soluções "fáceis demais"19, expondo os riscos camuflados pela conservação de uma atitude que naturaliza os elementos que constituem os nossos sistemas de pensamento.

Neste sentido, para Foucault, a própria significação e alcance do campo político aparecem ligados às consequências teóricas de um recuo filosófico exigido por uma abordagem arqueológica na problematização de nosso presente. Uma explicação geral do nome "arqueologia", conferido por Foucault ao tipo de estudo que realiza desde o início da década de 1960, é "a descrição do arquivo." ${ }^{20}$ Foucault não entende por arquivo a reunião de tudo o que foi dito em um período, nem muito menos o espírito de uma época. Descrever o arquivo seria traçar um jogo de regras que envolve a aparição e a desaparição dos enunciados em uma cultura na exterioridade material dos discursos. Com o uso da palavra "arqueologia" não se deve entender, portanto, um estudo que esteja interessado na busca de origem. Não se trata de uma referência à arqué grega (arkhê), como elemento básico ou fundamento

\footnotetext{
${ }^{17}$ FOUCAULT, "Sur les façons d'écrire l'histoire”, Dits et écrits I, p. 588.

${ }^{18}$ FOUCAULT, "Entretien de Michel Foucault avec André Berten”, Mal faire, dire vrai. Fonction de l'aveu en justice, p. 243.

19 "Fazer a crítica, isto é tornar difíceis os gestos fáceis demais". FOUCAULT, "Est-il donc important de penser?", Dits et écrits $I V$, p. 180.

${ }^{20}$ FOUCAULT, "Réponse à une question", Dits et écrits I, p. 681.
} 
original. Mas, antes, de uma análise que trabalha sobre o arquivo, que "aparece, então, como um tipo de grande prática de discursos, prática que tem suas regras, suas condições, seu funcionamento e seus efeitos." 21 Trata-se, então, de um trabalho sobre os enunciados que se opõe à história das ideias focada na interpretação do que estaria silenciosamente nas entrelinhas dos discursos, como se seus segredos essenciais residissem em um não-dito.

Como afirma a intérprete Colette Ysmal, Foucault opõe sua arqueologia à história das ideias porque essa última faria do discurso "somente um 'efeito de superfície', a projeção de processos situados em outros lugares e, notadamente, nisso que chamamos o pensamento, a pura e simples expressão de uma atividade intelectual que, no limite, poderia acontecer sem o discurso." 22 A arqueologia recusa a suposição de uma consciência ou de um pensamento do sujeito como aquilo que organizaria o trabalho histórico. Tal suposição partiria do postulado moderno de um sujeito como transcendental, assegurando sua capacidade de decifração do mundo e de direcionamento da história. Antes, para Foucault, é preciso um trabalho crítico que permita entender como as práticas históricas criam condições de possibilidade para formação de sujeitos no interior de regimes discursivos. Deste modo, na sua arqueologia, o sujeito não é a fonte de sentido dos discursos capaz de pensar fora de suas amarras. Atentando aos estudos contemporâneos sobre a linguagem e o inconsciente elaborados pela "contra-ciências" 23 modernas, seria preciso admitir que o sujeito "não é um, mas cindido, não mais soberano, mas dependente, não mais origem absoluta, mas função sempre modificável." 24 Cindido pelas significações múltiplas que o antecedem e o atravessam, dependente das práticas históricas que o constituem e dão forma aos seus saberes, o sujeito funciona de modos diversos no interior de regras discursivas variáveis. No recuo crítico exigido pela arqueologia, as configurações históricas plurais que condicionam o pensamento devem ser interrogadas através de um eixo que não é o do pensamento de um sujeito intransponível na linguagem - pensamento sempre fora de alcance e da possibilidade de demonstração. Trata-se de organizar o trabalho a partir do eixo daquilo que realmente foi enunciado em um discurso que servirá de material para a validação da análise.

$\mathrm{Na}$ descrição do arquivo, os enunciados aparecem como materiais históricos a serem trabalhados como "monumentos." 25 Estudar os enunciados como monumentos quer dizer interditar qualquer atribuição de inteligibilidade a eles que não seja justificada no trabalho comparativo e laborioso sobre um conjunto definido daquilo que realmente foi dito. Como afirma Luca Paltrinieri, transformar os discursos "em monumentos significa os colocar em relação uns com os outros para estabelecer o jogo de diferenças que os torna comparáveis entre si, que estabelece suas vizinhanças e suas distâncias". ${ }^{26}$ Contra a busca de significações abstratas que não são atestadas no que realmente foi enunciado, a arqueologia foucaultiana enfatiza a importância do trabalho sobre os discursos na "dimensão de sua exterioridade". ${ }^{27}$

\footnotetext{
${ }^{21}$ FOUCAULT, "La naissance d'un monde", Dits et écrits I, p. 787.

${ }^{22}$ YSMAL "Histoire et archéologie", p. 782.

${ }^{23}$ FOUCAULT, Les mots et les choses, p. 391.

${ }^{24}$ FOUCAULT, "La naissance d'un monde", Dits et écrits I, p. 789.

${ }^{25}$ FOUCAULT, L'archéologie du savoir, p. 15.

${ }^{26}$ PALTRINIEIRI, L'expérience du concept, p. 133.

${ }^{27}$ FOUCAULT, "Réponse à une question", Dits et écrits I, p. 682.
} 
Qualquer inteligibilidade histórica deve ser justificada nos jogos de regras encontrados na superfície própria dos discursos. Com este princípio, a análise da constituição histórica de sistemas de pensamento torna complexo e denso o trabalho sobre discursos, exigindo uma fundamentação na materialidade dos enunciados, e não num sentido fundamental ou na sua origem. Deste modo, na arqueologia os próprios discursos aparecem caracterizados por uma espessura e complexidade ignoradas quando se dá prosseguimento aos mitos de uma "história para filósofos". ${ }^{28}$ É o jogo difícil e meticuloso das regras históricas dos discursos que deve ser interrogado, não a consciência do autor ou o espírito de uma época. Trata-se de evitar os procedimentos de negação da existência de regras históricas do discurso, para "emancipar a história do pensamento de sua sujeição transcendental". ${ }^{29}$ Alerta aos perigos de considerar o discurso como mera expressão de uma consciência antecedente, faz-se necessário considerá-lo enquanto prática que, envolvida em condições de existência variáveis, produz diferentes sistemas de pensamento.

Para Foucault, os temas transcendentais atuantes na história das ideias confeririam não só uma excessiva simplificação na análise dos sistemas de pensamento, mas também uma grande indulgência a certa visão política da história. ${ }^{30}$ Desta forma, o questionamento acerca da metodologia histórica aplicada na análise dos sistemas de pensamento mostra-se um problema político fundamental no embate entre a arqueologia e os seus adversários teóricos. Este tema da relação entre a análise discursiva e a política é abordado diretamente por Foucault no texto Resposta a uma questão. ${ }^{31}$

Neste texto, publicado em maio de 1968 na revista Esprit, Foucault responde às críticas políticas que lhe são feitas após a publicação de As palavras e as coisas. Trata-se de um dos textos que irá servir de base na redação do livro $A$ arqueologia do saber. Respondendo, então, aos leitores da Esprit, Foucault encara a seguinte questão: como, com os princípios teóricos da sua arqueologia, principalmente com as noções de "coerção do sistema" e de "descontinuidade na história do espírito", ele não estaria preso no dilema político de ter de optar entre "a aceitação do sistema" ou "o apelo ao acontecimento selvagem, à irrupção de uma violência exterior, única capaz de transformar o sistema?"32 Tal pergunta lhe é dirigida a partir de uma perspectiva humanista, na qual o homem, enquanto ser coletivo, é o ator que deve tomar consciência de sua situação e agir politicamente na construção do sentido histórico. Anteriormente, em seu livro de 1966, Foucault havia atacado este postulado do homem, chamando-o de uma figura histórica criada pelo sistema de pensamento moderno e destinada a desaparecer como "um rosto na areia" 33 . Ora, para o humanismo, se aceitássemos tal argumentação, isto é, se considerássemos que o homem não é o protagonista de sua história, como, então, seria possível transformar o sistema em que nos encontramos? Não estaríamos presos ao acaso dos acontecimentos quando aceitamos abrir mão da consciência humana enquanto motor de sua própria emancipação dialética? Em resumo, para os

\footnotetext{
${ }^{28}$ FOUCAULT, "Foucault répond à Sartre", Dits et écrits I, p. 666.

${ }^{29}$ FOUCAULT, L'archéologie du savoir, p. 264.

${ }^{30}$ FOUCAULT, "Réponse à une question", Dits et écrits I, p. 687.

${ }^{31}$ FOUCAULT, "Réponse à une question”, Dits et écrits I, pp. 673-695.

${ }^{32}$ FOUCAULT, "Réponse à une question”, Dits et écrits I, p. 673.

${ }^{33}$ FOUCAULT, Les mots et les choses, p. 398.
} 
humanistas, Foucault levaria o pensamento a um dilema intransponível à ação política progressista que almeja a realização da liberdade humana na história.

Tal censura dos leitores da Esprité baseada em críticas como as de Sartre. É bastante conhecida a passagem em que Sartre acusa o caráter ideológico de As palavras e as coisas, chamando as teses do livro de "a última barragem que a burguesia pode construir contra Marx." 34 Na leitura de Olivier Revault d'Allonnes, também vemos a consideração de $A s$ palavras e as coisas como uma tentativa de mascarar a realidade. O livro lançaria "poeira nos olhos"35 ao fazer com que não se enxergue os movimentos que "existem na sociedade, não na estrutura." 36 Para Revault d'Allonnes, assim como para Sartre, o caráter ideológico presente não só na pesquisa foucaultiana, mas em todo movimento identificado como estruturalista - estaria em uma valorização exagerada no estudo dos sistemas estáticos que impediria a percepção das mudanças, explicadas unicamente pela atuação humana na história. Seja na linguagem, seja nas instituições históricas, mesmo que seja possível fazer um estudo das estruturas como inertes e desligadas da vontade humana, isso não deveria impedir a percepção de que tais estruturas foram criadas pelo homem, podendo ser transformadas somente por meio da sua ação. ${ }^{37}$ É a dimensão da originalidade e do devir que seria negligenciada quando se privilegia um estudo de ordens estáticas. Dito de outra maneira, enquanto Foucault se preocuparia exclusivamente com certa imobilidade do que já foi dito, organizando o sistema de significação no interior de discursos passados, para a filosofia humanista seria preciso mostrar que estes discursos ganham sua significação por quem os profere. Assim, a mesma oposição entre estrutura e devir, presente na pergunta dirigida pelos leitores da Esprit a Foucault, aparece também nas críticas advindas dos filósofos humanistas. Sendo o homem a fonte de sentido dos discursos, é ele quem poderá fazer o novo emergir para além do que já está instituído. O ataque ao homem é visto, então, como um ataque à liberdade em relação às estruturas.

No entanto, caso nos situemos na perspectiva filosófica que emerge justamente na oposição ao humanismo, poderíamos formular outros questionamentos: por que precisaríamos admitir o homem como o criador do novo e o protagonista da história para vislumbrar as transformações das significações instituídas? Esta figura do homem como doador de sentido não seria ela mesma uma amarra às novas formas de pensamento? Respondendo às censuras de seus críticos, Foucault repete ao seu modo uma tese nietzscheana: "Ora, o homem sujeito, o homem sujeito de sua própria consciência e de sua própria liberdade, ele é no fundo um tipo de imagem correlata de Deus." 38 Nascida no século XIX junto às ciências humanas, esta imagem do homem tem na filosofia de Feuerbach uma formulação bastante representativa do humanismo moderno. Trata-se da recuperação na coletividade humana sobre a terra daquilo que outrora foi concedido aos céus. Um pensamento que concede os atributos divinos ao homem conserva, no fundo, uma forma antiga do pensamento. Assim como acontece no humanismo de Feuerbach, também as teses

\footnotetext{
${ }^{34}$ SARTRE, "Jean-Paul Sartre répond", p. 76.

${ }^{35}$ REVAULT d'ALLONNES, "Michel Foucault : les mots contre les choses”, p. 170.

${ }^{36}$ REVAULT d'ALLONNES, "Michel Foucault : les mots contre les choses", p. 163.

${ }^{37}$ SARTRE, "Jean-Paul Sartre répond", p. 78-79.

${ }^{38}$ FOUCAULT, "Foucault répond à Sartre”, Dits et écrits I, p. 664.
} 
ateístas de um existencialismo humanista não passariam, como afirma Maurice Blanchot, de "pura pretensão. Diz-se ateu, diz-se pensar o homem, mas é sempre Deus como luz e como unidade que se continua a reconhecer." ${ }^{39}$ Contra a religião, o humanismo recusa-se a pensar Deus como origem de sentido. Entretanto, o homem é alçado ao lugar divino quando, saindo do sono dogmático, entramos no sono antropológico. ${ }^{40}$ Neste "sono novo" da modernidade, acredita-se encontrar na essência do homem "o fundamento do conhecimento, a definição de seus limites e, finalmente, a verdade de toda verdade" ${ }^{\text {" }}$. Fechando os olhos para os limites de nossa finitude, conserva-se em nossos tempos a presunção daqueles que ainda querem "propor uma moral". ${ }^{42} \mathrm{E}$ assim, nas diferentes teleologias modernas que preservam "as figuras gêmeas da antropologia e do humanismo" "43, a ação humana estaria destinada a realizar o "devir da razão"44 na história. Em poucas palavras, sustentando os temas transcendentais, o humanismo se oporia apenas superficialmente ao pensamento dogmático, pois reserva à sua ação política um poder de revelação de uma verdade e de um sentido histórico atemporais. A crítica existencialista à arqueologia aparece inteiramente dependente do sistema discursivo humanista moderno analisado em As palavras e as coisas, carregando com este sistema uma concepção reduzida do que seria a política.

Deste modo, vemos que, na resposta aos leitores da revista Esprit, Foucault resume as quatro operações críticas da sua arqueologia construídas na superação do sistema de pensamento humanista. A primeira operação crítica arqueológica é, segundo Foucault, a recusa dos temas transcendentais de um antropologismo que é imposto ao campo discursivo "pela filosofia do século XIX." 45 A filosofia dialética teria na história o último refúgio do pensamento antropológico, prometendo ao homem um retorno à sua verdade. Em oposição, ao procurar mostrar o pertencimento do humanismo a um sistema discursivo recente, a arqueologia libertaria as práticas discursivas como objeto de análise. A segunda operação crítica da arqueologia viria da eliminação das dicotomias pouco refletidas, tais como a oposição entre estrutura e devir frequentemente retomadas pelos seus críticos. Ao invés de fazer uma história do pensamento pressupondo oposições entre dinamismo e estabilidade, mediocridade e genialidade ou qualquer outra metáfora utilizada para designar a diferença entre o instituído e a criação de algo novo, a arqueologia faz a "análise do campo das diferenças simultâneas (que definem a uma época dada a dispersão possível do saber) e das diferenças sucessivas (que definem o conjunto das transformações, suas hierarquias, suas dependências, seus níveis). ${ }^{46}$ Em terceiro lugar, a arqueologia busca a superação da recusa em se considerar o discurso em sua própria existência. Ou seja, a recusa "de reconhecer que

\footnotetext{
${ }^{39}$ BLANCHOT, L'Entretien infini, p. 377.

40 "Designada sob seu próprio nome, ou oculta em outros projetos, a Antropologia, ou pelo menos o nível antropológico da reflexão, tenderá a alienar a filosofia”. FOUCAULT, Gênese e estrutura da Antropologia de Kant, p. 95.

${ }^{41}$ FOUCAULT, Les mots et les choses, p. 352.

${ }^{42}$ FOUCAULT, Les mots et les choses, p. 339

${ }^{43}$ FOUCAULT, L'archéologie du savoir, p. 22.

${ }^{44}$ FOUCAULT, L'archéologie du savoir, p. 262.

${ }^{45}$ FOUCAULT, "Réponse à une question", Dits et écrits I, p. 684.

${ }^{46}$ FOUCAULT, "Réponse à une question", Dits et écrits I, p. 685.
} 
no discurso algo é formado (segundo regras bem definíveis); que esse algo existe, subsiste, se transforma, desaparece (segundo regras igualmente definíveis)". ${ }^{47}$ As regras formadas nas relações entre palavras e coisas que constituem nossa realidade histórica podem ser analisadas em suas condições de coexistência, de preservação e de transformação. Todavia, os temas de uma grande história do espírito excluíam a análise das regras discursivas que singularizam os regimes históricos de pensamento. Concluindo, a quarta operação crítica diz respeito à liberação do estatuto incerto do conjunto de disciplinas da história do pensamento. A arqueologia rejeita nessas disciplinas a descrição confusa de relações entre causalidades políticas, sociais e econômicas com certa história do pensamento. Delimitando com rigorosidade o campo de pesquisa para descrever as formas de relações que as práticas discursivas poderão ter com outros domínios históricos, a arqueologia propõe a análise do discurso "nas suas condições de formação, na série das suas modificações e no jogo de suas dependências e de suas correlações. $O$ discurso aparece assim em uma relação descritível com o conjunto de outras práticas". ${ }^{48}$ Deste modo, para Foucault, a análise do discurso deve levar em conta relações específicas que articulam as práticas discursivas com práticas distintas. Contra o relacionamento confuso de causalidades oriundas de dimensões distintas, a arqueologia opõe o estudo do discurso como conteúdo analítico preciso, o que não quer dizer isolado de outras práticas. Assim, contra o projeto de uma "história global", que permite a si mesma a reunião de elementos heterogêneos em torno de um princípio único, a arqueologia apresenta-se como projeto de uma "história geral" 49 que "desdobraria, ao contrário, o espaço de uma dispersão". ${ }^{50}$ Esta história geral arqueológica deve descrever a singularidade das práticas, o jogo de suas relações e a forma de suas dependências reconhecendo a necessidade de delimitação de seu campo de estudo. Sua análise resguarda certa autonomia da prática discursiva, reconhecendo-a, no entanto, sempre relativa, visto que as práticas discursivas não estão isoladas de outras práticas. A correlação das práticas não quer dizer que uma reflete ou expressa a outra, mas somente que existem relações que devem ser analisadas em suas especificidades.

Estas quatro operações críticas da arqueologia aparecem, então, como princípios teóricos que, simultaneamente, possibilitam o estudo do discurso em sua materialidade e impedem

as perigosas facilidades que se permite a política [...] se ela se dá a garantia de um fundamento originário ou de uma teleologia transcendental, se ela goza de um

\footnotetext{
${ }^{47}$ FOUCAULT, "Réponse à une question", Dits et écrits I, p. 686.

${ }^{48}$ FOUCAULT, "Réponse à une question", Dits et écrits I, p. 686.

${ }^{49}$ Como afirma Ysmal, "História geral que se opõe à história global, à história dos séculos e das épocas, mas também à história concebida em termos de reflexo ou de expressão. A história geral reconhece, com efeito, a autonomia relativa de cada discurso e aquela do discurso em relação ao campo não-discursivo [...] A história de um discurso e aquela de vários discursos compreende, portanto, de direito e por necessidade, a história desse campo com o qual o discurso ou vários discursos têm uma relação de articulação ou de engrenagem. História geral é a das historicidades diferentes das quais é preciso pensar ao mesmo tempo a diferença e a relação. YSMAL, "Histoire et archéologie. Note sur la recherche de Michel Foucault", p. 803.

${ }^{50}$ FOUCAULT, L'archéologie du savoir, p. 19.
} 
constante uso de metáfora sobre o tempo pelas imagens da vida ou os modelos do movimento, se ela renunciava a tarefa difícil de uma análise geral das práticas, de suas relações, de suas transformações, para se refugiar em uma história global das totalidades, das relações expressivas, de valores simbólicos e de todas estas significações secretas investidas nos pensamentos e nas coisas. ${ }^{51}$

A política, levando-se em conta as críticas da arqueologia, não poderá mais ser pensada como o lugar da realização de uma verdade transcendental oposta aos discursos ideológicos. Contra a perigosa visão da política ligada à verdade do homem, o campo da análise discursiva traz variados elementos para pensarmos uma política outra, possibilitando repensar o sentido e o alcance do que entendemos como política. Ainda, na resposta de Foucault aos leitores da Esprit, vemos que a pesquisa arqueológica traz ao domínio político o problema "do status, das condições de exercício, do funcionamento, da institucionalização dos discursos científicos." 52 Trata-se de questionar a dimensão política dos discursos científicos, reprovando a pressuposição de neutralidade da ciência. Considerando os discursos científicos no interior dos sistemas históricos de pensamento tratados como acontecimentos, a dimensão política do funcionamento destes discursos não é dissociável de suas práticas internas ou correlatas. Assim, a análise das práticas discursivas permite demarcar, sem reduzir a multiplicidade das dependências, os papéis da relação entre diferentes práticas políticas e o funcionamento interno de regras dos discursos científicos. Isso se torna possível porque ela analisa os sistemas de pensamento em suas condições históricas de possibilidade. Estas abarcam variadas práticas, impedindo que estas sejam vistas como totalmente heterogêneas.

\section{CONCLUSÃO}

Partimos da questão sobre a política no pensamento de Foucault, mas logo vimos que a pressuposição de um pensamento do autor não se adequa às críticas e aos princípios teóricos de seu trabalho. Vimos, então, como sua crítica à função autor traz consigo a crítica dos temas transcendentais contrários à análise das práticas discursivas. Assim, mostramos uma relação entre a análise arqueológica e a ampliação do campo da política que se dá justamente na politização dos sistemas de pensamento interrogados em suas condições históricas de possibilidade. Esperamos ter mostrado como o recuo crítico arqueológico procura impedir uma visão sobre a política nos termos antropológicos. Nega-se, portanto, a conceber a ação política como uma tomada de consciência do homem face à estagnação das estruturas da linguagem. Longe de impedir a prática da liberdade em relação aos sistemas de saber, para a arqueologia, seria através da tarefa específica do "diagnóstico do presente",53 que a filosofia contribuiria politicamente ao exercício de liberdade. É neste sentido que devemos ler a passagem seguinte, localizada nas últimas páginas de $A$ arqueologia do saber: "Eu não neguei, longe disso, a possibilidade de mudar o discurso: tirei dele o direito exclusivo e

\footnotetext{
${ }^{51}$ FOUCAULT, “Réponse à une question", Dits et écrits I, p. 687.

${ }^{52}$ FOUCAULT, "Réponse à une question", Dits et écrits I, p. 688.

${ }^{53}$ FOUCAULT, “Foucault répond à Sartre”, Dits et écrits I, p. 665.
} 
instantâneo à soberania do sujeito." 54 Ou seja, o estudo arqueológico, enquanto análise das condições históricas de possibilidade dos discursos, concebe a si mesmo justamente como uma busca pelas possibilidades de um exercício político de liberdade em relação ao pensamento moderno, visto que este se revelaria preso em amarras transcendentais. Essa busca, que se constitui enquanto prática de liberdade, torna-se possível justamente ao negar um caráter unitário ao real. Negação esta, que se manifesta no pluralismo da análise arqueológica das práticas discursivas. Assim, na rejeição de certa naturalização dos saberes modernos, a arqueologia estaria envolvida politicamente na confrontação dos limites do pensamento atual. Em outras palavras, no movimento de recusa do humanismo, no movimento de libertação em relação aos seus pressupostos, a arqueologia foucaultiana afirma a tarefa política de construção de novas e plurais perspectivas ao pensamento. Será através desta politização dos saberes em trabalhos específicos e rigorosos que Foucault se arriscará em um exercício constante de transformação de si.

\section{POLITICS AND DISCOURSE ANALYSIS IN FOUCAULT'S ARCHAEOLOGY}

Abstract: The article seeks to explore the relationship between discourse analysis and politics in Michel Foucault's archaeology. The paper begins by raising the question about the way one could approach his work, since he criticizes the author function. We will show that this approach already constitutes itself as one of the theoretical principles of his archaeology. We will then investigate how the critical operations of his analysis of discursive practices lead to a politicization of knowledge, which is made in opposition to the modern anthropological thought.

Keywords: Foucault - politics - speech - archaeology - author.

\section{REFERÊNCIAS BIBLIOGRÁFICAS}

BLANCHOT, M. L'Entretien infini. Paris: Gallimard, 1969.

FOUCAULT, M. Naissance de la clinique. Paris: Presses Universitaires de France, 1963.

Les mots et les choses: une archéologie des sciences humaines. Paris: Gallimard, 1966.

L'arquéologie du savoir. Paris: Éditions Gallimard, 1969.

L'ordre du discours. Paris: Éditions Gallimard, 1971.

. Histoire de la folie à l'âge classique. Paris: Éditions Gallimard, 1972.

Dits et écrits vol. I. Paris: Éditions Gallimard, 1994.

${ }^{54}$ FOUCAULT, L'archéologie du savoir, p. 272. 
. Dits et écrits vol. IV. Paris: Éditions Gallimard, 1994.

. Le beau danger. Entretien avec Claude Bonnefoy. Paris: Éditions de l'EHESS, 2011.

Mal faire, dire vrai. Fonction de l'aveu en justice. Louvain-la Neuve: Presses universitaires de Louvain, 2012.

MUCHAIL, S. T. "Michel Foucault e o dilaceramento do autor", in: Revista Margem, no 16, 2002, pp. 129-135. Versão online: http://www4.pucsp.br/margem/pdf/m16sm.pdf

PALTRINIERI, L. L'expérience du concept: Michel Foucault entre épistémologie et histoire. Paris: Publications de la Sorbonne, 2012.

REVAULT D'ALLONNES, O. "Michel Foucault: les mots contre les choses". Raison Presente, 1967. In: Les mots et les choses de Michel Foucault - Regards critiques 1966-1968. Presses universitaires de Caen - IMEC éditeur, 2009.

SARTRE, J-P. "Jean-Paul Sartre répond”. L'Arc, 1966. In: Les mots et les choses de Michel Foucault Regards critiques 1966-1968. Presses universitaires de Caen - IMEC éditeur, 2009.

YSMAL, C. "Histoire et archéologie. Note sur la recherche de Michel Foucault", in: Revue française de science politique, vol.XXII, $\mathrm{n}^{\circ}$ 4, 1972, pp.775-804. 